Electronic Supplementary Information for:

Phenylboronic Acid-Dopamine Dynamic Covalent Bond

Involved Dual-Responsive Polymeric Complex: Construction and

\title{
Anticancer Investigation
}

Huan-Ying Liu, ${ }^{\ddagger}$ Zhu Qiao ${ }^{\star}$ Xiao-Xu Mao, Jie-Cheng Zha, and Jun Yin*

Department of Polymer Science and Engineering, School of Chemistry and Chemical

Engineering, Hefei University of Technology and Anhui Province Key Laboratory of Advanced

Catalytic Materials and Reaction Engineering and Biomedical and Environmental

Interdisciplinary Research Centre, Hefei 230009, P. R. China.

*Corresponding Author: yinjun@hfut.edu.cn (J.Y.)

These two authors contributed equally to this work.

The Supporting Information file is of 15 pages, 7 figures. 


\section{Instruments}

The ${ }^{1} \mathrm{H},{ }^{13} \mathrm{C}$, and ${ }^{19} \mathrm{~F}$ nuclear magnetic resonance (NMR) spectra were recorded using a Bruker $600 \mathrm{MHz}$ spectrometer operated in the Fourier Transform mode. Chemical shifts are reported in delta $(\delta)$ units and expressed in parts per million (ppm) downfield from tetramethylsilane using the residual proton solvent as an internal standard. Molecular weights and molecular weight distributions were determined using a size exclusion chromatograms (SEC) equipped with a Waters 1515 pump and a Waters 2414 differential refractive index detector ( set at $40^{\circ} \mathrm{C}$ ). A series of three linear Styragel columns (HR0.5, HR2, and HR4; $3.6 \times 300 \mathrm{~mm}$ ) was used at a temperature of $40{ }^{\circ} \mathrm{C}$. The eluent used was THF at a flow rate of $0.3 \mathrm{~mL} / \mathrm{min}$. FT-IR spectra were recorded on Perkin-Elmer Spectrum BX FT-IR system using $\mathrm{KBr}$ pellets at $25{ }^{\circ} \mathrm{C}$. UV-vis spectra were performed on UNIC $4802 \mathrm{UV} /$ vis double beam spectrophotometers. UV-vis spectra were performed on a UNIC 4802 UV/VIS double beam spectrophotometer in $1.0 \mathrm{~cm}$ length quartz cell. Fluorescence spectra were recorded using a RF-5301/PC (Shimadzu) spectrofluorometer. The temperature of the water-jacketed cell holder was controlled by a programmable circulation bath. The slit widths were set at $5.0 \mathrm{~nm}$ for both excitation and emission. Transmission electron microscopy (TEM) observations were conducted on a JEM-2100F electron microscope operating at an acceleration voltage of $200 \mathrm{kV}$. The samples for TEM observation were prepared by casting the corresponding solutions of polymers onto copper mesh grids and drying in air at room temperature. Dynamic light scattering (DLS) measurements were carried on a NanoZS90 Zetasizer of Malvern (UK) instrument, all data were averaged over three time measurements.

\section{Materials}

All solvents were obtained from Sinopharm. Co. Ltd. and were purified by the standard procedures before use. THF was further dried over sodium benzophenone ketyl and distilled onto $\mathrm{LiAlH}_{4}$ under nitrogen just before use. Nile red (NR) was purchased from Aladdin and used as received without further purification. $N$ Isopropylacrylamide (NIPAM, 97\%, Tokyo Kasei Kagyo Co.) was purified by 
recrystallization from a mixture of benzene and $n$-hexane $(1 / 3, v / v)$. Water was deionized with a Milli-Q SP reagent water system (Millipore) to a specific resistivity of 18.0 $\mathrm{M} \Omega \mathrm{cm}$. The $\mathrm{Pd}(\mathrm{II})$ functionalized trithiocarbonate (PCMA-Pd) and pentafluorophenyl acrylate (PFPA) were synthesized according to previously reported literatures, ${ }^{1,2}$ correlated synthetic procedure and ${ }^{1} \mathrm{H}$ NMR spectra were shown in Figures $\mathrm{S} 1$ and $\mathrm{S} 2$. The hydrogen peroxide $\left(\mathrm{H}_{2} \mathrm{O}_{2}\right)$ responsive and tetraphenylethene (TPE) functionalized phenyl isocyanide monomers, HBPI and TPEPI, were directly used from the same batch as in our previously reported work. ${ }^{3,4}$

\section{Sample Preparation}

Synthesis of Alkynyl Functionalized Trithiocarbonate (PCMA-alkynyl). The synthesis procedure was shown in Figure S1a. For example, propargylamine $(60.6 \mathrm{mg}, 1.1 \mathrm{mmol})$, 2-(propylthio-carbonothioylthio)-2-methylpropionoic acid (PCMA) (0.24 g, $1.0 \mathrm{mmol}$ ), 1-ethyl-3-(3-dimethylaminopropyl) carbodiimide hydrochloride (EDCI; (0.2 g, 1.0 mmol), and DMAP (0.1 g, $0.85 \mathrm{mmol})$ were dissolved in dichloromethane $(20.0 \mathrm{~mL})$. After stirring at room temperature for $24 \mathrm{~h}$, the reaction mixture was diluted in dichloromethane and washed with water and brine. The combined organic layer was dried over $\mathrm{MgSO}_{4}$ and evaporated to dryness. The residue was purified by silica gel column to afford the final PCMA-alkynyl as a yellow solid (yielding: $\sim 83 \%$ ).

Synthesis of Pd(II) Functionalized Trithiocarbonate (PCMA-Pd). This compound was synthesized according to a reported procedure with little modifications. ${ }^{5,6}$ Typically, into a dichloromethane $(10 \mathrm{~mL})$ solution of PCMA-alkynyl $(0.14 \mathrm{~g}, 0.5 \mathrm{mmol})$ and triethylamine $(10 \mathrm{~mL}), \quad$ trans-dichlorobis(triethylphosphine)palladium $(0.21 \mathrm{~g}, 0.5$ mmol) and copper(I) chloride $(3.16 \mathrm{mg}, 0.03 \mathrm{mmol})$ were added. The mixture was allowed to stir at room temperature for $12 \mathrm{~h}$. After the solvent was removed by evaporation under reduced pressure, the residue was purified by column chromatography with ethyl acetate and petrol ether $(\mathrm{v} / \mathrm{v}=4 / 1)$ as eluent, affording the final PCMA-Pd as a yellow oil (yielding: 76\%). 
Preparation of PNIPAM-Pd macroinitiator. Polymerization of PNIPAM macroinitiator was conducted by RAFT polymerization according to a procedure similar to the reported literatures. ${ }^{7}$ Typically, PCMA-Pd (100 mg, 0.15 mmol), NIPAM (510 mg, 4.5 mmol; $\left.[\mathrm{M}]_{0} /[\mathrm{I}]_{0}=30\right)$, and AIBN $(2.5 \mathrm{mg}, 0.015 \mathrm{mmol})$ were dissolved in $3.0 \mathrm{~mL}$ of 1,4-dioxane. The mixture was degassed through three freeze-thaw cycles, and then sealed under vacuum and kept in an oil bath preheated at $70{ }^{\circ} \mathrm{C}$ to conduct the polymerization. After $8 \mathrm{~h}$, the ampule was put into liquid nitrogen to stop the polymerization. The reaction mixture was diluted with $3 \mathrm{~mL}$ of 1,4-dioxane and precipitated into an excess of diethyl ether. This purification cycle was repeated twice. The obtained yellow PNIPAM-Pd powder (yielding: 80\%) was dried in a vacuum oven overnight at room temperature.

Preparation of PNIPAM-b-P(HBPI-co-TPEPI) Copolymers. This copolymer was synthesized according to the reported literature with little modification. ${ }^{8}$ For example, HBPI (140 mg, $\left.0.4 \mathrm{mmol} ;[\mathrm{M}]_{0} /[\mathrm{I}]_{0}=20\right)$, TPEPI (95 mg, $\left.0.2 \mathrm{mmol} ;[\mathrm{M}]_{0} /[\mathrm{I}]_{0}=10\right)$ in $1.0 \mathrm{~mL}$ THF was added into a THF solution $(0.5 \mathrm{~mL})$ of PNIPAM-Pd $(70 \mathrm{mg}, 0.02$ mmol). The resulting mixture was stirred at $55{ }^{\circ} \mathrm{C}$ for $12 \mathrm{~h}$ and then poured into an excess of diethyl ether. This purification cycle was repeated twice. The resultant copolymer was isolated via centrifugation and dried under vacuum, affording the final PNIPAM- $b$-P(HBPI-co-TPEPI) as an umber solid.

The Deprotection of Pinanediol from Boronate Esters. This procedure was followed by reported literatures. ${ }^{9,10}$ Typically, sodium periodate $(100 \mathrm{mmol})$ was added into a solution of PNIPAM- $b$-P(HBPI-co-TPEPI) $(5.0 \mathrm{mmol}$; $[\mathrm{PBA}]=50 \mathrm{mmol})$ with $\mathrm{THF} / \mathrm{H}_{2} \mathrm{O}$ at a volume ratio of $3 / 1$ at room temperature, and then suitable $2.0 \mathrm{~N} \mathrm{HCl}$ was added. The mixture was allowed to stir at room temperature for $5 \mathrm{~h}$, and then concentrated under vacuum and poured into a large amount of diethyl ether, affording the final PNIPAM- $b$-P(PBAPI-co-TPEPI).

Synthesis of Pentafluorophenyl Acrylate (PFPA). This compound was synthesized according to a reported literature. ${ }^{11}$ Pentafluorophenol $(3.3 \mathrm{~g}, 18 \mathrm{mmol})$ and triethylamine $(2.68 \mathrm{~mL}, 19 \mathrm{mmol})$ was dissolved in $50 \mathrm{~mL}$ of anhydrous 
dichloromethane under $\mathrm{N}_{2}$ atmosphere at $0^{\circ} \mathrm{C}$. Then, acryloyl chloride $(1.56 \mathrm{~mL}, 18.64$ mmol) was added dropwise into the solution for $10 \mathrm{~min}$, and the reaction was allowed to stir for another 2 hours at room temperature. The conversion was monitored by thinlayer chromatography with hexane/EtOAc $=4 / 1$ as eluent until the complete consumption of pentafluorophenol was observed. The reaction mixture was filtered prior to extraction with brine and dried over sodium sulfate. The residue was further purified by silica gel column to afford the final PFPA monomers as clear oil.

Preparation of P(PFPA-co-OEGA) Copolymers. The polymerization was conducted according to the procedure similar to a reported literature. ${ }^{1}$ For example, 2-(propylthiocarbonothioylthio)-2-methylpropionoic acid (11.92 mg, $0.05 \mathrm{mmol})$, AIBN (1.23 mg, $0.005 \mathrm{mmol})$, OEGA (0.4 g, $\left.1.5 \mathrm{mmol} ;[\mathrm{M}]_{0} /[\mathrm{I}]_{0}=30\right)$ and PFPA $(0.18 \mathrm{~g}, 0.75 \mathrm{mmol}$; $\left.[\mathrm{M}]_{0} /[\mathrm{I}]_{0}=15\right)$ were dissolved in $2.0 \mathrm{~mL}$ of 1,4 -dioxane. The mixture was degassed through three freeze-thaw cycles, and then sealed under vacuum and kept in an oil bath preheated at $70{ }^{\circ} \mathrm{C}$ to conduct the polymerization. After $12 \mathrm{~h}$, the ampule was put into liquid nitrogen to stop the polymerization. The reaction mixture was diluted with $3 \mathrm{~mL}$ of 1,4-dioxane and precipitated into an excess of diethyl ether. This purification cycle was repeated twice. The obtained yellow P(PFPA-co-OEGA) copolymers (yielding: $\sim 70 \%$ ) were dried in a vacuum oven overnight at room temperature.

Functionalization of P(PFPA-co-OEGA) Copolymers with Dopamine. This reaction was performed in a similar way to reported literatures. ${ }^{12,13}$ The P(PFPA-co-OEGA) copolymer $(0.15 \mathrm{~g}, 0.02 \mathrm{mmol}$; $[\mathrm{PFPA}]=0.16 \mathrm{mmol})$ and dopamine hydrochloride (35.5 mg, $0.2 \mathrm{mmol}$ ) were dissolved in $5.0 \mathrm{~mL}$ of dry $N, N$-dimethylformamide (DMF). Excess dopamine hydrochloride was used to ensure the complete conversion of the reactive pentafluorophenyl ester groups into catechol-based amide moieties. After purging argon for $15 \mathrm{~min}$, triethylamine $(19 \mathrm{mg}, 0.25 \mathrm{mmol})$ was added dropwise and the mixture was stirred at room temperature. After stirring for $6 \mathrm{~h}$, the obtained copolymer was filtered to remove the salt and re-dissolved in 5.0 mL of DMF. The redissolution and filtration process was repeated three times. The DMF solution was 
precipitated twice into hexane and diethyl ether $(\mathrm{v} / \mathrm{v}=1 / 1)$ and dried overnight, affording the final P(DA-co-OEGA) copolymers (yielding: 80\%).

Self-Assembly of P1. Typically, $4.0 \mathrm{mg}$ of $\mathrm{P} 1$ was dissolved in $0.5 \mathrm{~mL}$ of THF, the solution was stirred and maintained for $30 \mathrm{~min}$ at room temperature. Under vigorous stirring, $1.5 \mathrm{~mL}$ of DI water was added via a syringe pump at a flow rate of $0.05 \mathrm{~mL} / \mathrm{min}$. After the addition was completed, the dispersion was left stirring for another $4 \mathrm{~h}$. THF was then removed by dialysis (MWCO $3.5 \mathrm{kDa}$ ) against pure water for $24 \mathrm{~h}$. Fresh water was replaced approximately every $6 \mathrm{~h}$. The obtained dispersion with a characteristic of colloidal aggregates did not exhibit any macroscopic phase separation upon standing at room temperature for more than 7 days, suggesting the formation of stable aggregates.

Preparation of NR-Loaded Polymeric Complex. Hydrophobic NR molecules were loaded into the $\mathrm{C} 1$ complex during the co-solvent self-assembly process. Typically, the initial concentrations of P1, P2, and NR in THF were 3.0, 2.4, and $0.01 \mathrm{~g} / \mathrm{L}$, respectively. A similar self-assembly procedure was then performed upon a slow water ( $\mathrm{pH} 8.5$ ) addition as detailed above. The final mixture was vacuumed to remove the organic solvent. Free NR was removed by passing through a $0.22 \mu \mathrm{m}$ Millipore filter. The final complex dispersion was diluted with phosphate buffer solution (PBS; $\mathrm{pH}$ 7.4). To determine the content of NR, an aliquot of NR@C1 was dissolved in DMSO. The NR encapsulation efficiency and loading content were calculated to be $\sim 58.4 \mathrm{wt} / \mathrm{wt} \%$ and $\sim 5.56 \mathrm{wt} / \mathrm{wt} \%$ based on the fluorescence emission of NR at $625 \mathrm{~nm}$ against standard calibration curves. Encapsulation efficiency $(\%)=($ weight of molecules in the micelles / weight of the feeding molecules $) \times 100 \%$; Loading content $(\%)=($ weight of molecules $)$ $/$ (weight of molecules + weight of polymer $) \times 100 \%$. Following the same procedure, CPT/NR@C1 complex was also prepared.

In Vitro NR Release Profile. The cargo release from NR@C1 complex was measured by a dialysis method. Briefly, the NR@C1 dispersion $(1.0 \mathrm{~g} / \mathrm{L} ; 10.0 \mathrm{~mL})$ was placed in a dialysis tube (MWCO $3.5 \mathrm{kDa}$ ) and then immersed into $500 \mathrm{~mL}$ of water (pH 5.5 and 7.4) with Tween 20 (1.0\% total volume) under gentle stirring at $37^{\circ} \mathrm{C}$. At different time 
intervals, $20 \mathrm{~mL}$ external water solution was removed and replaced with equal volume of fresh water. The separated solution was lyophilized and then dissolved in DMSO, the NR concentration was quantified by measuring the fluorescence emission against a standard calibration curve.

In Vitro Fluorescence Imaging. Fluorescence images of NR@C1 internalized HeLa cells were acquired using an inverted Leica SP2 confocal microscope at $37{ }^{\circ} \mathrm{C}$. The samples were excited at $550 \mathrm{~nm}$ for NR, and the fluorescence was collected between 580-700 $\mathrm{nm}$ for the red channel. All confocal laser scanning microscopy (CLSM) images were taken under the same conditions for parallel comparison.

Cell Culture and in Vitro Cytotoxicity Assessment. HeLa cells $\left(5 \times 10^{3}\right.$ cells/well) in Dulbecco's modified Eagle's medium (DMEM) complete medium were plated into a 96-well plate and incubated overnight. Then, the cells were exposed to $\mathrm{C} 1$ complex with different concentrations at $37^{\circ} \mathrm{C}$ for up to $12 \mathrm{~h}$ in DMEM complete medium. Then, cells were rinsed with PBS buffer and DMEM complete medium. Cytotoxicity was assessed by adding 3-(4,5-dimethyl-2-thiazolyl)-2,5-diphenyl tetrazolium bromide (MTT) for another 4h. Cells incubated with blank polymeric micelles were served as positive control.

\section{REFERENCES}

(1) Zhang, W. M.; Zhang, J.; Qiao, Z.; Liu, H. Y.; Wu, Z. Q.; Yin, J. Polym. Chem., 2018, 9, 4233-4242.

(2) Han, X.; Zhang, J.; Qiao, C. Y.; Zhang, W. M.; Yin, J.; Wu, Z. Q. Macromolecules, 2017, 50, 4114-4125.

(3) Chen, Y.; Zhang, Z. H.; Han, X.; Yin, J.; Wu, Z. Q. Macromolecules, 2016, 49, 77187727.

(4) He, Y. G.; Shi, S. Y.; Liu, N.; Ding, Y. S.; Yin, J.; Wu, Z. Q. Macromolecules, 2016, $49,48-58$. 
(5) Xue, Y. X.; Zhu, Y. Y.; Gao, L. M.; He, X. Y.; Liu, N.; Zhang, W. Y.; Yin, J.; Ding, Y. S.; Zhou, H. P.; Wu, Z. Q. J. Am. Chem. Soc. 2014, 136, 4706-4713.

(6) Jiang, Z. Q.; Zhao, S. Q.; Su, Y. X.; Liu, N.; Wu, Z. Q. Macromolecules 2018, 51, 737-745.

(7) Zhao, Y. J.; Wu, Y.; Chen, S.; Deng, H. P.; Zhu, X. Y. Macromolecules 2018, 51, 5234-5244.

(8) Couttst, S. J.; Adams, J.; Krolikowski, D.; Snow, R. J. Tetrahedron Ltters. 1994, 35, 5109-5112.

(9) Morera, E.; Marzo, V. D.; Monti, L.; Allarà, M.; Moriello, A. S.;Nalli, M.;Ortar, G.; Petrocellis, L. D. Bioorg. Med. Chem. Lett 2016, 26, 1401-1405.

(10) Coen, R.D.; Vanparijs, N.; Risseeuw, M. D. P.; Lybaert, L.; Louage, B.; Koker, S.D.; Kumar, V.; Grooten, J.; Taylor, L.; Ayres, N.; Calenbergh, S. V.; Nuhn, L.; Geest, Br. G. D. Biomacromolecules 2016, 17, 2479-2488.

(11) Basuki, J. S.; Duong, H. T. T.; Macmillan, A.; Whan, R.; Boyer, C.; Davis, T. P.; Macromolecules 2013, 46, 7043-7054.

(12) Xu, L. Q.; Chen, J. C.; Wang, R.; Neoh, K. G.; Kang, E. T.; Fu, G. D. A. RSC Adv. 2013, 3, 25204.

(13) Li, L.; Yan, B.; Yang, J. Q.; Huang, W. J.; Chen, L. Y.; Zeng, H. B. ACS Appl. Mater. Interfaces 2017, 9, 9221-9225. 


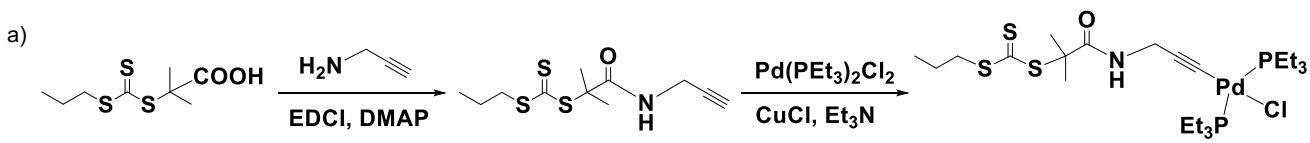

b)
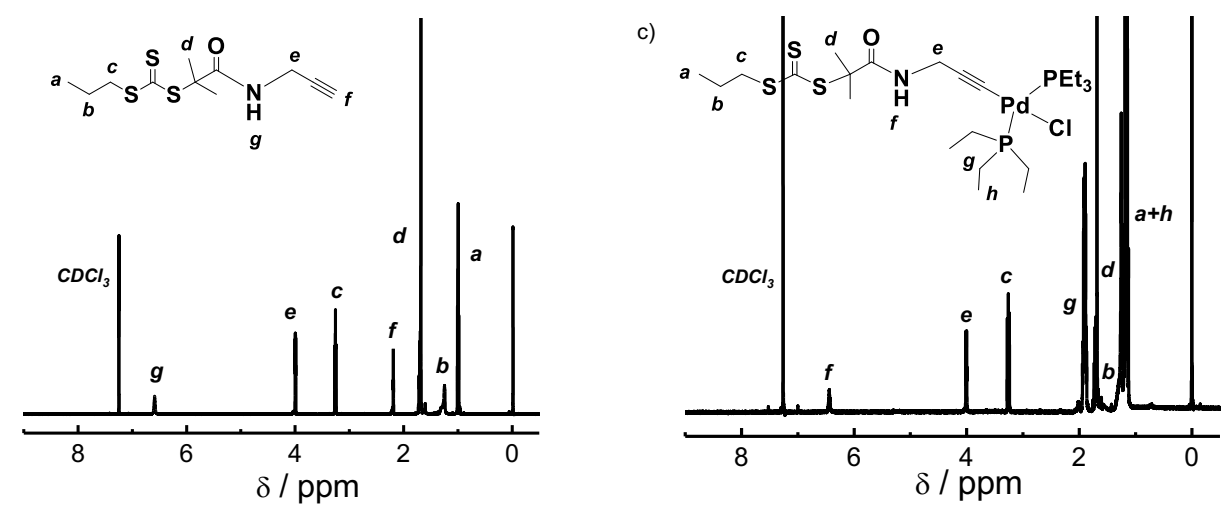

Figure S1. (a) Synthetic routes employed for the preparation of $\mathrm{Pd}(\mathrm{II})$ functionalized trithiocarbonate (PCMA-Pd). ${ }^{1} \mathrm{H}$ NMR spectra of (b) alkynyl-functionalized trithiocarbonate (intermediate) and (c) PCMA-Pd measured in $\mathrm{CDCl}_{3}$ at $25^{\circ} \mathrm{C}$. 
a)<smiles>C=CC(=O)Oc1c(F)c(F)c(F)c(F)c1OC(=O)C=CC</smiles>

b)

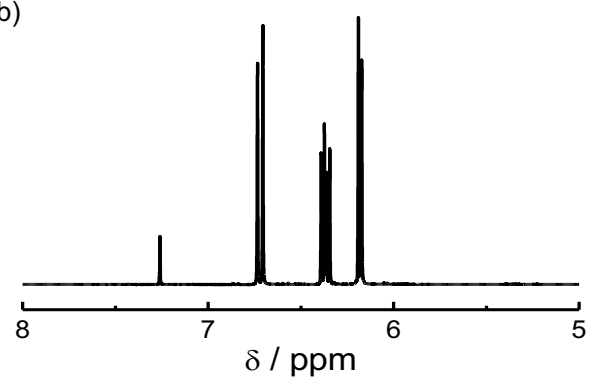

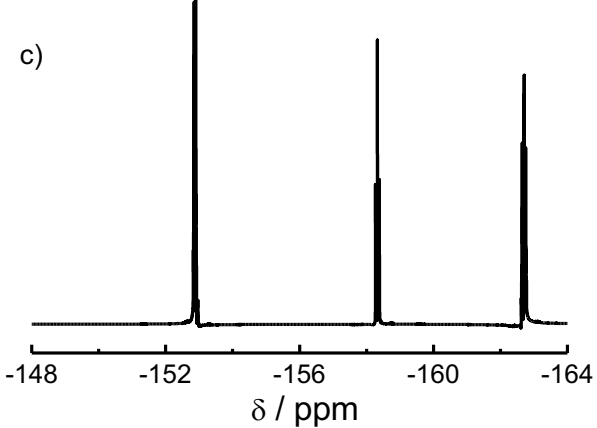

Figure S2. (a) Synthetic route employed for the preparation of pentafluorophenyl acrylate (PFPA). (b) ${ }^{1} \mathrm{H}$ and (c) ${ }^{19} \mathrm{~F}$ NMR spectra of PFPA measured in $\mathrm{CDCl}_{3}$ at $25{ }^{\circ} \mathrm{C}$. 

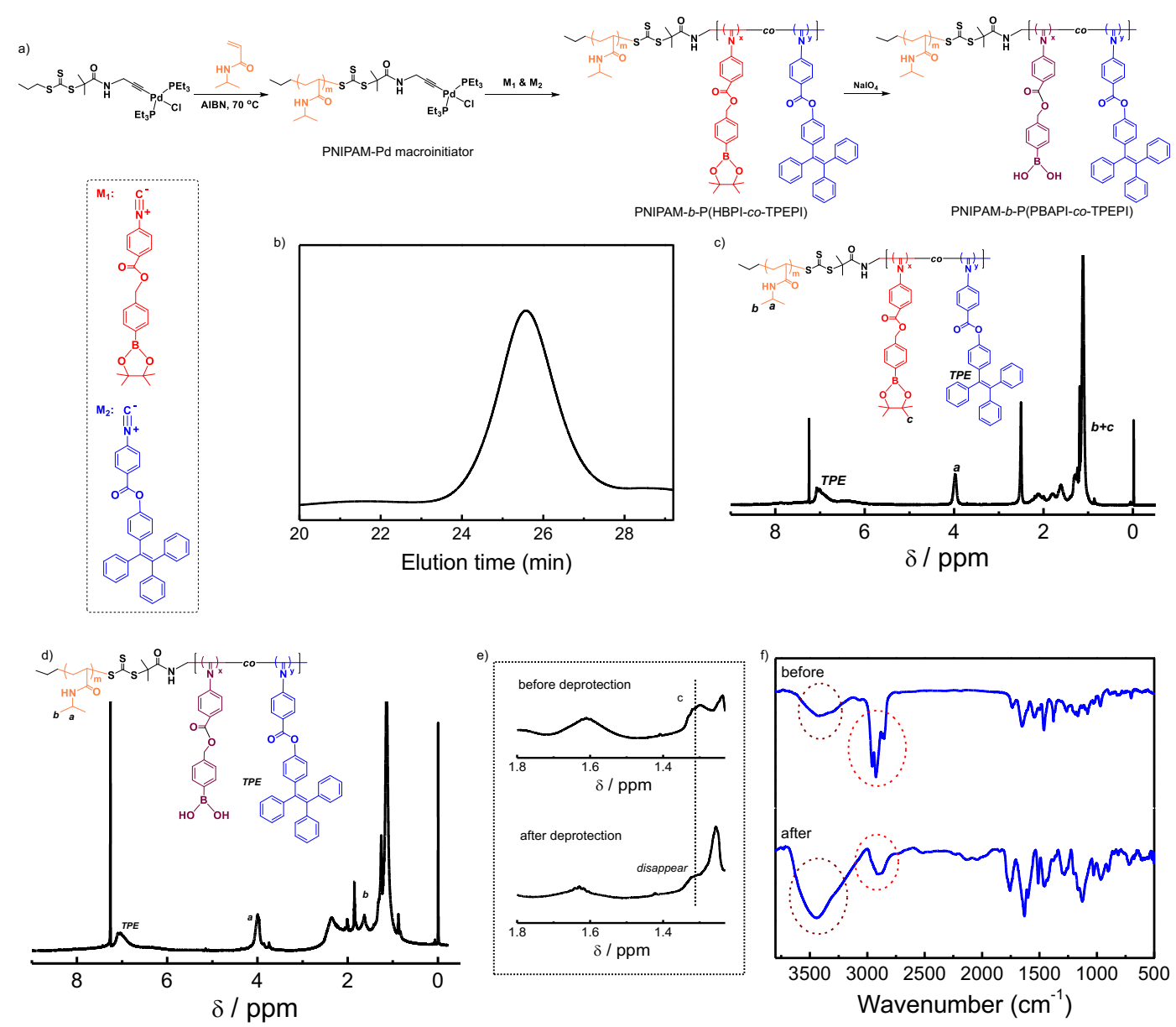

Figure S3. (a) Synthetic routes employed for the preparation of PNIPAM- $b$ - P(PBAPI$c o$-TPEPI) copolymer. (b) SEC trace obtained for PNIPAM- $b$ - P(HBPI-co-TPEPI) copolymer using THF as eluent. ${ }^{1} \mathrm{H}$ NMR spectra of (c) PNIPAM- $b$-P(PBAPI-coTPEPI) and (d) PNIPAM- $b$-P(HBPI-co-TPEPI) copolymers measured in $\mathrm{CDCl}_{3}$ at $25^{\circ} \mathrm{C}$. Figure e illustrated the partial magnified area of Figures $\mathrm{c}$ and d. (f) FT-IR spectra obtained for PNIPAM- $b$ - P(PBAPI-co-TPEPI) copolymer before (top) and after (down) treatment with sodium periodate at $25^{\circ} \mathrm{C}$ using $\mathrm{KBr}$ pellets. 
a)

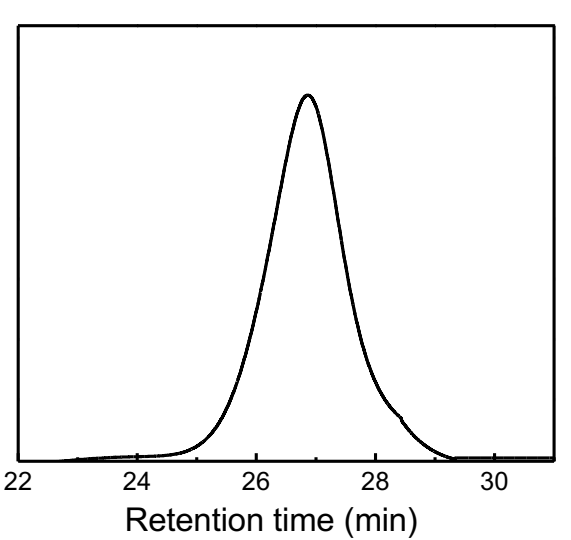

b)

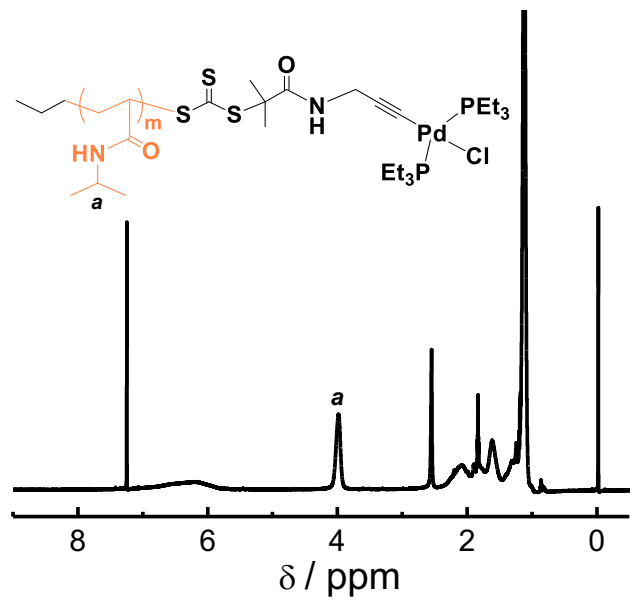

Figure S4. (a) SEC trace obtained for homo-PNIPAM intermediate using THF as eluent.

(b) ${ }^{1} \mathrm{H}$ NMR spectrum of homo-PNIPAM intermediate measured in $\mathrm{CDCl}_{3}$ at $25{ }^{\circ} \mathrm{C}$. 


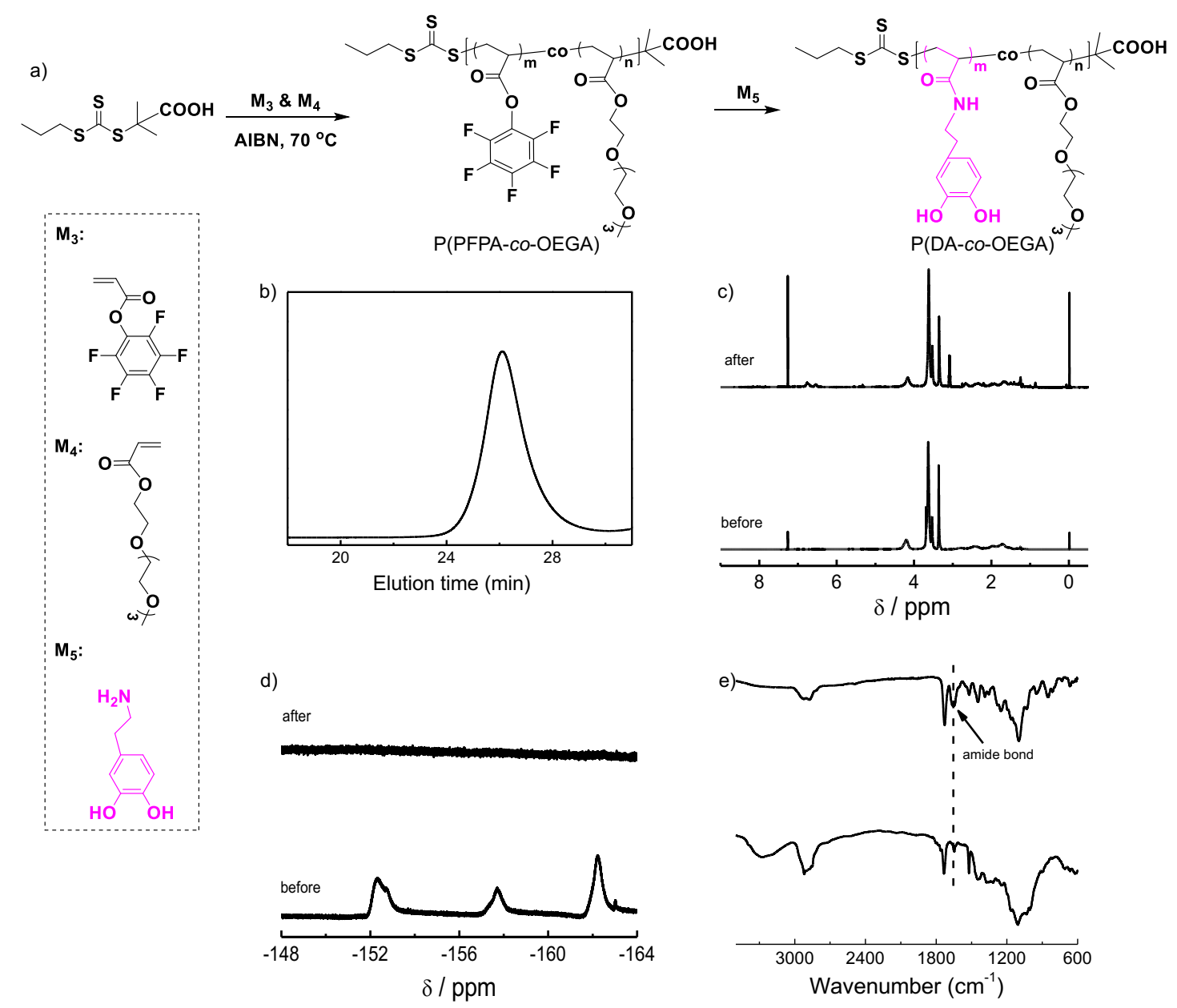

Figure S5. (a) Synthetic routes employed for the preparation of P(DA-co-OEGA) copolymer. (b) SEC trace obtained for P(PFPA-co-OEGA) copolymer using THF as eluent. (c) ${ }^{1} \mathrm{H}$ and (d) ${ }^{19} \mathrm{~F}$ NMR spectra of P(PFPA-co-OEGA) copolymer before (down) and after (top) substitution reaction (activated ester chemistry) with DA molecules. (e) FT-IR spectra obtained for P(PFPA-co-OEGA) (down) and P(DA-co-OEGA) (up) copolymers at $25^{\circ} \mathrm{C}$ using $\mathrm{KBr}$ pellets. 

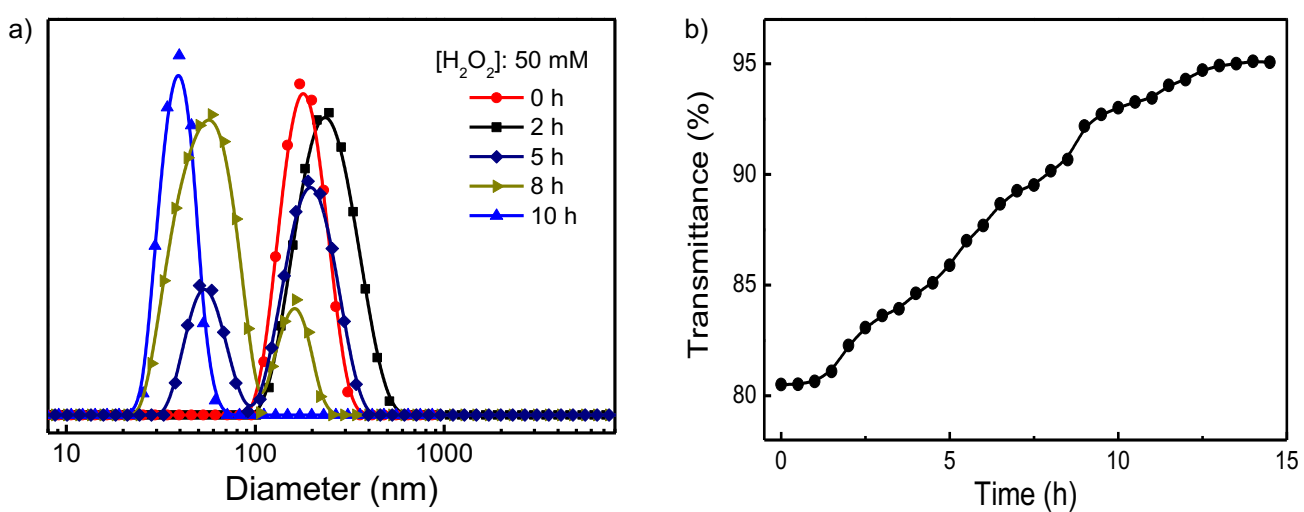

Figure S6. (a) Hydrodynamic diameter distribution and (b) time dependence of optical transmittance at a wavelength of $700 \mathrm{~nm}$ obtained for the aqueous dispersion of PNIPAM- $b$-P(HBPI-co-TPEPI) micelles at different times in the presence of $50 \mathrm{mM}$ of $\mathrm{H}_{2} \mathrm{O}_{2}$ and $20{ }^{\circ} \mathrm{C}$. 

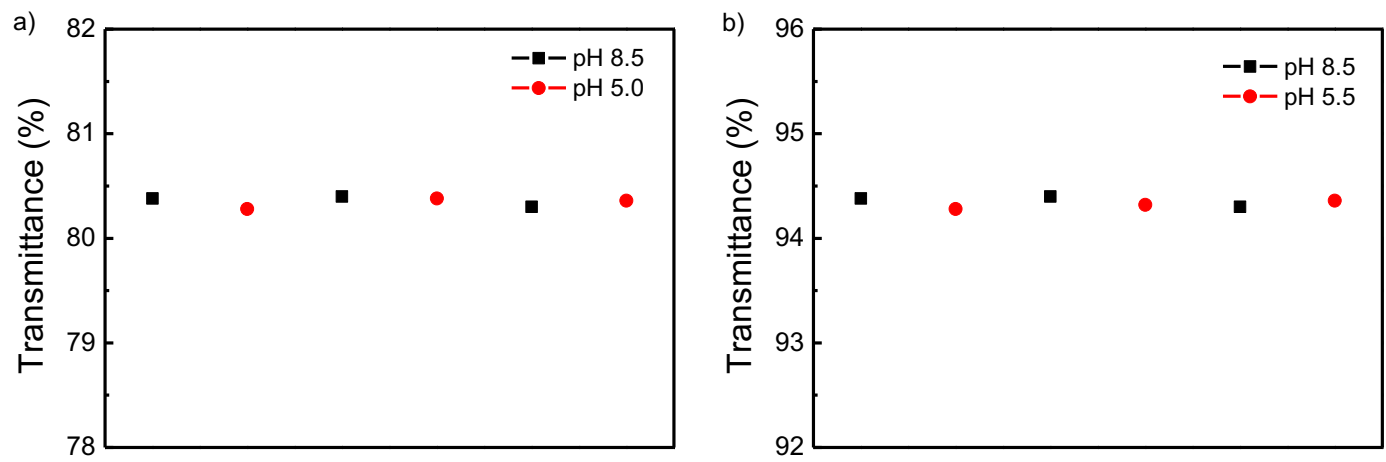

Figure S7. pH dependent optical transmittance at a wavelength of $700 \mathrm{~nm}$ obtained for the aqueous dispersion of (a) P1 and (b) P2 for several cycles at $20{ }^{\circ} \mathrm{C}$. 